\title{
AVALIAÇÃO DAS TECNOLOGIAS DIGITAIS NA DOCÊNCIA: INDICADORES BRASILEIROS E PORTUGUESES
}

RONALDO NUNES LINHARES

MARIA JOSÉ LOUREIRO

FERNANDO RAMOS

CAIO MÁRIO GUIMARÃES ALCÂNTARA

\section{RESUMO}

Este artigo apresenta um grupo de indicadores voltados para avaliar o uso das Tecnologias da Informação e Comunicação na docência, que foram sugeridos por professores do Brasil e Portugal que atuaram em programas de uso de tecnologias digitais em seus países. A pesquisa constitui uma investigação qualitativa, com aplicação de questionários e realização de entrevistas e grupos focais, junto a professores da região da cidade de Aveiro, norte de Portugal, e dos municípios de Nossa Senhora da Glória, Tobias Barreto e Itabaiana, no estado de Sergipe, Brasil. As respostas desses professores ressaltam a necessidade do estabelecimento de indicadores avaliativos que considerem aspectos qualitativos da docência mediada por tecnologias digitais.

PalaVRas-chave AVAliAçÃo - tecnologias digitais • DOCÊNCIA • INDICADORES EDUCACIONAIS. 


\section{EVALUACIÓN DE LAS TECNOLOGÍAS DIGITALES EN LA DOCENCIA: INDICADORES BRASILEÑOS Y PORTUGUESES \\ RESUMEN}

Este artículo presenta un grupo de indicadores que se destinan a evaluar el uso de las Tecnologías de Información y Comunicación en la docencia, sugeridos por profesores de Brasil y Portugal que actuaron en programas de uso de tecnologías digitales en sus países. La investigación constituye un estudio cualitativo, con aplicación de cuestionarios y realización de entrevistas y grupos focales junto a profesores de la región de la ciudad de Aveiro, norte de Portugal, y de los municipios de Nossa Senhora da Glória, Tobias Barreto y Itabaiana, en el estado de Sergipe, Brasil. Las respuestas de tales docentes subrayaron la necesidad de establecer indicadores evaluativos que consideren aspectos cualitativos de la docencia mediada por tecnologías digitales.

PALABRAS CLAVE EVALUACIÓN • TECNOLOGÍAS DIGITALES • DOCENCIA • INDICADORES EDUCACIONALES.

EVALUATION OF TEACHING DIGITAL TECHNOLOGIES: BRAZILIAN AND PORTUGUESE INDICATORS

ABSTRACT

This article presents a set of indicators suggested by teachers and aimed to evaluate the use of information and communication technologies in teaching practices. These indicators were selected by teachers from Brazil and Portugal working with digital technology programs in their countries. The study is a qualitative research that contains questionnaires, interviews and focus groups with teachers in the region of Aveiro, Northern Portugal and in the cities of Nossa Senhora da Glória, Tobias Barreto and Itabaiana, in the State of Sergipe, Brazil. The teachers' responses highlight the need for establishing evaluative indicators that consider qualitative aspects of teaching mediated by digital technologies.

KEYWORDS EVALUATION • DIGITAL TECHNOLOGIES • TEACHING • EDUCATIONAL INDICATORS. 


\section{INTRODUÇÃO}

As discussões acerca da relação entre a aprendizagem e as tecnologias comunicacionais têm se tornado cada vez mais relevantes, em especial quando se considera o atual cenário da educação. Hoje é preciso pensar as práticas pedagógicas no contexto das sociedades informacionais (ORGANIZAÇÃO DAS NAÇÕES UNIDAS PARA A EDUCAÇÃO, A CIÊNCIA E A CULTURA - UNESCO, 2008a). A formação dos sujeitos que no futuro vão desempenhar atividades no mercado de trabalho passa a ser pautada numa busca incessante pelo crescimento da produção (CARVALHO, 2011) e transferência de tecnologia e conhecimento. Esses são dois dos fatores considerados primordiais para a transformação social por organismos como a Organização das Nações Unidas para a Educação, a Ciência e a Cultura (Unesco), sem que, no entanto, seja ignorada a necessidade de formação voltada para um uso reflexivo e que contribua para a formação de indivíduos competentes para o convívio na nova ordem social.

Nas últimas duas décadas, foram verificadas algumas tentativas de consolidação de políticas públicas educacionais 
voltadas para preencher essa lacuna no processo de formação dos sujeitos competentes para o uso das Tecnologias da Informação e Comunicação (TIC) e sua inclusão digital. Dessas experiências, destacamos, no Brasil, o Programa Um Computador por Aluno (Prouca) e, em Portugal, o Projeto Magalhães, ambos com o objetivo de incentivar novos olhares sobre a relação com o conhecimento e construir novas práticas de ensino inseridas na realidade contemporânea. Apesar de observados esforços no sentido de consolidar o uso das TIC enquanto dispositivo pedagógico, é notória, na elaboração de políticas públicas, a falta de propostas de acompanhamento e avaliação desse uso, por meio da construção de instrumentos e indicadores avaliativos.

Entre 2012 e 2014, foram entrevistados professores de quatro unidades de ensino portuguesas, situadas em Aveiro e cercanias, e três unidades brasileiras do estado de Sergipe, com o objetivo de identificar e discutir os potenciais e os limites do uso dos computadores móveis na prática docente. A experiência desses professores com a utilização de computadores e tecnologias móveis auxiliou na identificação dos pontos considerados exitosos e daqueles que dificultam o desenvolvimento das atividades junto aos alunos, servindo de alicerce uma discussão sobre a necessidade de definir melhor os indicadores considerados mais relevantes numa proposta de avaliação do trabalho desses professores com as TIC.

A percepção dos docentes a respeito de sua experiência com a utilização de tecnologias móveis serviu de base para a sugestão de indicadores que, segundo eles, são mais adequados para avaliação das TIC na docência. Este artigo apresenta o resultado do estudo entre professores portugueses e brasileiros envolvidos no Projeto Magalhães, em Portugal, e no Prouca, no Brasil, com uma reflexão sobre o conjunto de indicadores sugeridos pelos professores. Comparam-se as percepções dos professores e suas sugestões, distinguindo as mais e as menos relevantes, na tentativa de compreender o lugar das TIC nas diversas dimensões da prática docente. 


\section{INDICADORES NA AVALIAÇÃO DAS TIC NO ESPAÇO ESCOLAR}

No contexto dos novos arranjos sociotécnicos, a prática docente passa a desempenhar um papel que vai além da mera reprodução dos conteúdos distribuídos nas diversas disciplinas existentes nos currículos da educação compulsória. Gengnagel e Nicolodi (2012) defendem a consolidação de um modelo educacional propício para a disseminação de sujeitos com pensamento e raciocínio críticos sobre um modelo de vida fortemente influenciado pela ciência e tecnologia. Esses cidadãos e, por conseguinte, as escolas que os formam devem ter estimulada a capacidade de convívio com as constantes mudanças impostas pelo avanço tecnológico.

Consideradas importantes aliadas dos professores, as TIC contribuem para as mudanças das abordagens pedagógicas de um modelo centrado no falar-ditar para os que propiciam aos alunos a autoria, interação e colaboração, num processo de estímulo à autonomia dos processos de aprendizagem. Para Silva (2006), o docente deve compreender as diversas possibilidades provenientes do uso das TIC enquanto dispositivo pedagógico, tais como: oferta de múltiplas informações (em imagens, sons, textos); ensejo de diferentes percursos para conexões e expressões com o que os alunos possam contar no ato de manipular informações; e estímulo a cada aluno que contribui com novas informações, criando e oferecendo mais e melhores caminhos durante a aprendizagem.

Essa realidade, pela qual a (r)evolução tecnológica tornou-se um fator intermitente, exige uma capacitação ininterrupta por parte dos sujeitos, no sentido de ampliar as perspectivas no tocante à capacidade de uso significativo, produção e compartilhamento de informações para o conhecimento. Castells (1999, p. 23) explica que

\footnotetext{
[...] as novas tecnologias da informação não são apenas ferramentas para se aplicar, mas processos para se desenvolver. [...] Pela primeira vez na história a mente humana é uma força produtiva direta.
}

Na prática, a produção intelectual e de conhecimento passa a balizar todos os ciclos da economia e cultura no mundo.

Nesse sentido, em países como Brasil e Portugal, foram implantadas, nos últimos 25 anos, políticas públicas de 
inclusão digital centradas na inserção das TIC e no acesso à internet no espaço escolar, visando a atender a Agenda Digital, proposta pelo Livro Verde para a sociedade da informação, lançado em 1997 em Portugal e em 2000 no Brasil (TAKAHASHI, 2000). Respeitando pequenas diferenças, esses documentos propõem ações de consolidação da sociedade da informação nos respectivos países em todos os seus aspectos, dos quais destacam-se ampliação do acesso, meios de conectividade, formação de recursos humanos, incentivo à pesquisa e ao desenvolvimento, comércio eletrônico e desenvolvimento de novas aplicações, considerando a educação um elemento motriz para a consolidação da sociedade informacional, voltada para preparar cidadãos para a aprendizagem contínua (TAKAHASHI, 2000).

Considerando tal contexto e baseado no projeto "One Laptop per Child", ${ }^{1}$ foi criado no Brasil, em 2007, o Prouca e, em 2008, no âmbito do projeto Magalhães, foi lançado o E_escolinha em Portugal, ambos correspondendo a uma tentativa ampla de inserção dos dispositivos midiáticos nas salas de aula e ambientes de aprendizagem. Criados numa nova 1 Projeto criado pelos pesquisadores Nicholas Negroponte e Seymour Papert, do Media Lab do Massachusetts Insitute of Technology (MIT). O projeto foi lançado em 2005 no Fórum Econômico Mundial (ALVAREZ, 2015) fase de integração das TIC à educação, tanto o Prouca quanto o projeto Magalhães tinham como objetivos instituir um programa que permitisse acesso contínuo a computadores e internet com condições especiais para a comunidade escolar e promover o desenvolvimento de novas práticas de aprendizagem a serem implementadas em todo o país. Outros pontos positivos são: redução da exclusão digital; democratização do acesso a computadores; disponibilização de bons softwares; e possibilidade de instauração de uma revolução tecnológica nas escolas (SOUSA, 2009).

Uma vez verificada a necessidade de utilização das TIC com finalidades pedagógicas, compreender o papel do professor nessa nova abordagem de ensino é uma ação que se faz urgente (CORTEZ; LAU, 2009). Os docentes são sujeitos ativos nos processos educacionais, mesmo nos modelos que privilegiam a autogestão dos estudos por parte dos alunos. Em outras palavras, para estimular um uso efetivo das tecnologias da comunicação nos espaços educacionais, é preciso levar em conta o conjunto de habilidades e competências 
adquiridas pelos professores com e para o uso das tecnologias informacionais e das mídias. São essas competências que agem no sentido de dirimir algumas dificuldades inerentes à integração das TIC enquanto instrumento técnico, tais como o gap de gerações entre professores e alunos, os problemas na formação inicial e continuada, além das implicações existentes na relação todos-todos no processo de comunicação escolar.

Os estudos e pesquisas, no Brasil e em Portugal, que acompanharam as experiências desses dois programas são responsáveis por comprovar a premissa de que a existência e o uso de computadores nas escolas não se traduzem em melhoria do desempenho escolar. Para que ele ocorra é necessária uma integração das práticas pedagógicas com a nova realidade socioeconômica, possível somente com a adoção de um novo olhar de alunos e professores sobre a tecnologia e por meio da prática inovadora. Esse conceito é apregoado por relatórios que reportam estudos direcionados à questão do uso das TIC por professores, emitidos por diversas instituições, dentre as quais Unesco (2008a, 2008b), Organização dos Estados Ibero-Americanos/Instituto para o Desenvolvimento e Inovação Educativa (OEI/IDIE)/Fundação Telefônica (2008), Unesco/Comissão Econômica para a América Latina e o Caribe (Cepal) (2006), Comitê Gestor da Internet no Brasil (2016), Kennisnet Foundation (2015) e Banco Mundial (2015).

Os relatórios traçam um panorama das questões relativas à avaliação do impacto das TIC na prática docente por meio de indicadores, elementos utilizados nos processos de avaliação, que contribuem para disponibilizar dados mais consistentes para análise e compreensão da realidade. Trata-se de ferramentas ligadas à gestão (ASOCIACIÓN ESPAÑOLA DE NORMALIZACÓN Y CERTIFICACIÓN - AENOR, 2003) e voltadas para a mensuração de fenômenos, servindo como subterfúgio para a tomada de decisões. São de natureza indutiva, pois partem da análise de linhas gerais para inferir padrões universais e possuem características próprias, definidas por Sierra (2012) como: pertinência; validez; confiabilidade; factibilidade; comunicabilidade; comparabilidade; resistência à manipulação; e vínculo com os objetivos. 
Apesar dos avanços alcançados nas questões referentes à relação professores/alunos/tecnologia, ainda persiste uma lacuna quando se pensa na avaliação desse uso ou, mais especificamente, do impacto e resultados dessas tecnologias no espaço escolar. Alguns dos relatórios de avaliação trazem reflexões e até mesmo contribuições na forma de instrumentos e estratégias de avaliação, no entanto, não atendem ou reconhecem a forma como os professores pensam a construção de indicadores destinados a mensurar o êxito e os limites da utilização das TIC nas práticas docentes.

Diferentemente dos relatórios institucionais, que se pretendem mais amplos, os estudos acadêmicos, que na sua maioria são recortes de uma microrrealidade, observados com lentes e aporte metodológicos os mais diversos, não conseguem construir um mapa mais amplo do impacto das TIC na educação. Além disso, em se tratando de políticas públicas, o acompanhamento e avaliação da execução e impacto desses projetos na comunidade escolar se traduzem como um grande vazio. O Estado que impõe essas políticas não avalia o quanto elas contribuíram ou não para a realização dos objetivos propostos.

A percepção acerca da necessidade de avaliação das TIC ficou mais evidenciada a partir da última década do século XX, quando em diversos países, em especial os da comunidade de língua inglesa, começaram a ser desenvolvidos programas de verificação de resultados (ORGANISATION FOR ECONOMIC CO-OPERATION AND DEVELOPMENT - OECD, 1992). Os primeiros, e até hoje principais, programas de avaliação estão centrados na análise da aprendizagem dos alunos, elaborados e analisados pela comunidade externa à escola, mas também existem programas que avaliam as práticas docentes, esses na maioria das vezes desenvolvidos pelos pares ou superiores na hierarquia da gestão escolar (FERRER, 2006).

No que tange às metodologias de avaliação das TIC, pode-se versar sobre formatos diversos que, no entanto, são compostos por características similares. De um modo geral, essa avaliação é pragmática, voltada para a detecção de mudanças nas práticas, definição de usos, descrição, monitoramento e legitimação, sempre considerando os contextos nos quais 
estão inseridos os objetos analisados (MORDUCHOVICZ, 2006). Essa avaliação é sempre baseada em indicadores que são classificados como descritivos, explicativos, simples ou construídos, numa tipologia que os classifica como sendo de insumo, de acesso ou de resultado.

A essa altura, é preciso esclarecer a importância de se construírem indicadores que respondam claramente às necessidades de compreender o impacto das políticas na sociedade. A principal justificativa para a demanda por indicadores de avaliação reside no aperfeiçoamento da gestão de recursos escolares, quer sejam os econômicos ou humanos. É por meio da aplicação de instrumentos que utilizem esses indicadores que se torna possível mensurar, comparar, definir (ou redefinir), planejar e avaliar melhor as políticas e os investimentos públicos ou privados. São essas ações que possibilitarão a melhoria dos índices educacionais, o que se traduz na formação de sujeitos mais capacitados para a sociedade e o mercado de trabalho no contexto da informação.

\section{PERCURSO E RESULTADOS}

Para melhor compreender as práticas docentes com as TIC de professores brasileiros e portugueses, com vistas a identificar as opções desses professores relativas aos indicadores avaliativos do uso das TIC em sala de aula, contamos com a colaboração de um grupo composto por 17 professores da cidade de Aveiro e adjacências, região central de Portugal, e 20 professores brasileiros que atuam nas cidades de Nossa Senhora da Glória, Itabaiana e Tobias Barreto, localizadas no estado de Sergipe, região Nordeste do Brasil. Em comum, ambos os grupos trabalham com alunos das séries inicias do ensino fundamental e participam nos dois projetos que envolvem tecnologia em seus respectivos países (Magalhães/ Portugal e Prouca/Brasil).

O estudo teve como objetivos identificar a percepção dos professores sobre os projetos Magalhães e Prouca, as formas como avaliam o impacto do uso das TIC nos processos de ensino e aprendizagem e os indicadores que consideram os mais importantes para avaliar o uso das TIC. 
Os professores participaram de entrevistas individuais e em grupos que variavam de dois a oito docentes por vez, todas gravadas em áudio e vídeo, com consentimento dos mesmos, com um tempo médio de 50 a 60 minutos cada entrevista. Em Portugal eles foram inquiridos sobre: treinamento para utilização das TIC e do Projeto Magalhães; quando e como eles utilizam os computadores; como eles planejam o uso diário do dispositivo; experiência de uso na prática docente; pesquisa, uso, produção e disponibilização de conteúdos; e conhecimento, domínio e uso de softwares. Vale ressaltar que as mesmas perguntas foram reproduzidas junto aos professores brasileiros que trabalham com o Prouca. O Quadro 1 apresenta o número de professores por escola e país que aceitaram colaborar com a pesquisa.

QUADRO 1 - Número de professores que participaram da pesquisa como respondentes

\begin{tabular}{|c|c:c|}
\hline PAIS & ESCOLA & PROFESSORES \\
\hline \multirow{3}{*}{ Portugal } & A & 2 \\
\hline & B & 4 \\
\hline \multirow{3}{*}{ Brasil } & C & 3 \\
\hline & D & 8 \\
\hline & A & 8 \\
\hline & C & 9 \\
\hline
\end{tabular}

Fonte: Dados da pesquisa.

O conteúdo das entrevistas foi organizado em categorias que contribuíram para definir o primeiro grupo de indicadores, enquanto o segundo grupo foi definido a partir da análise dos relatórios nacionais e internacionais de avaliação de TIC na educação. A sugestão de 40 indicadores foi enviada, por e-mail, para os mesmos professores, em formato de questionário para validação e identificação daqueles que esse grupo indicou, por ordem de importância, como os mais relevantes e adequados para a avaliação do uso das TIC em sua prática docente. Foram analisados os questionários devolvidos por 14 professores portugueses e 11 brasileiros. 
2 Tomando como base o conceito proposto por Fisc Shwertner (1997, p. 4), os dispositivos pedagógicos "seriam mecanismos utilizados para constituir ou transformar a experiência de si e que podem ser tomados como constitutivos da subjetividade. É ele quem media as relações do sujeito consigo mesmo baseando-se em suas experiências, valores e ideias

pessoais"

A primeira análise a ser feita é a dos resultados obtidos a partir das entrevistas realizadas com os professores, que serviram para traçar um perfil geral de uso e maior compreensão da utilização das TIC enquanto dispositivo² pedagógico. As respostas indicam semelhanças nas abordagens e visões tanto dos professores brasileiros como dos portugueses em relação ao uso dos dispositivos disponibilizados pelo Prouca e pelo Projeto Magalhães nas mais diversas etapas do processo educacional, desde a formação até a utilização em sala de aula, havendo, porém, algumas discrepâncias.

Em relação à formação voltada ao uso das TIC, os dois grupos de professores afirmaram ter participado de cursos e propostas formativas, no entanto, eles indicam que essa formação não foi suficiente, em especial se considerados os programas em questão. O que eles alegam é que não houve instrução para lidar com os computadores entregues pelos governos do Brasil e de Portugal. A semelhança entre as respostas segue nas perguntas relativas ao uso e planejamento de atividades.

Nos dois países, foi verificado que as escolas não destinam um momento específico para planejamento das atividades a serem desenvolvidas durante o ano com o uso dos dispositivos. Por esse motivo, os professores planejam os trabalhos de forma individual e em casa. Todas as escolas que participaram da pesquisa determinam um único dia da semana para a utilização dos computadores. Isso demonstra uma completa falta de articulação entre os professores e a escola e pode configurar certa resistência da instituição escolar às tecnologias da comunicação. $\mathrm{O}$ fato de esses dispositivos serem utilizados em um momento específico, com data e hora marcadas, vai de encontro à proposta de inovação e, nesse caso, as TIC passam a ser apenas uma plataforma nova para reprodução de modelos e práticas antigas.

A falta de planejamento articulado entre os professores também prejudica o estabelecimento de projetos transversais, promotores de novas abordagens de aprendizagem, fazendo com que os trabalhos desenvolvidos em sala sejam voltados para os conteúdos de cada disciplina. Nesse aspecto, tanto nas escolas de Portugal como nas do Brasil, o uso dos dispositivos em projetos ocorria, geralmente, na disciplina 
de língua portuguesa. Os professores tendem a utilizar os computadores para elaboração de textos e apresentação em PowerPoint, sem produzir objetos audiovisuais e nem disponibilizar as apresentações para os alunos.

Outro ponto em comum entre os grupos de professores dos dois países é a forma como eles pensam e passam a utilizar as TIC em sua prática docente. No caso brasileiro, os professores informaram que não realizavam atividades com esses recursos antes do advento do Prouca. Por esse motivo, eles ainda demonstram certa resistência às abordagens baseadas nos dispositivos tecnológicos. Em Portugal, verificou-se certo desconhecimento desses recursos por parte dos professores, que julgam a aparência dos computadores - por considerarem o dispositivo semelhante a um brinquedo - e afirmam não aprovar o uso da internet, pois pode ser um campo fértil para práticas consideradas negativas para os processos de aprendizagem, como, por exemplo, o plágio.

Em todos os casos, os professores ressaltam que tanto o Projeto Magalhães como o Prouca têm contribuições positivas no processo de popularização do acesso às tecnologias, colaborando com as etapas de planejamento e aprendizagem. Nesse aspecto, as TIC tornam-se aliadas na diminuição do gap entre gerações (ALMEIDA; ASSISI, 2011), uma vez que, após serem capacitados para o uso desses dispositivos, os estudantes desempenham o papel de multiplicadores ao tornarem comum o uso dos mesmos em suas casas.

As semelhanças entre as respostas dadas na entrevista pelos participantes dos dois grupos seguem nas críticas feitas aos projetos. Nos dois casos, os professores indicaram como pontos negativos das experiências com as TIC promovidas pelos respectivos governos: falta de suporte técnico; falta de formação continuada; suspensão do projeto; e problemas com o acesso à internet.

O questionário apresentado aos professores, contendo 40 indicadores, tinha como finalidade estimular o posicionamento sobre quais os indicadores mais qualificados para avaliar melhor o impacto das TIC em sua prática docente. $\mathrm{O}$ Quadro 2 apresenta os dez indicadores considerados pelos professores portugueses e os dez indicadores considerados 
pelos professores brasileiros como imprescindíveis para avaliar as TIC na docência.

QUADRO 2 - Indicadores mais votados

\begin{tabular}{|c|c|}
\hline PORTUGAL & BRASIL \\
\hline $\begin{array}{l}\text { Frequência no uso de tecnologias na planificação, na } \\
\text { prática pedagógica e na avaliação }\end{array}$ & $\begin{array}{l}\text { Frequência no uso de tecnologias no planejamento, } \\
\text { na prática pedagógica e na avaliação }\end{array}$ \\
\hline $\begin{array}{l}\text { Estratégias e práticas pedagógicas desenvolvidas } \\
\text { com a utilização das TIC e centradas no ensino }\end{array}$ & $\begin{array}{l}\text { Estratégias e práticas pedagógicas desenvolvidas } \\
\text { com a utilização das TIC e centradas no ensino }\end{array}$ \\
\hline $\begin{array}{l}\text { Estratégias e práticas pedagógicas desenvolvidas } \\
\text { com a utilização das TIC e centradas na } \\
\text { aprendizagem }\end{array}$ & $\begin{array}{l}\text { Estratégias e práticas pedagógicas desenvolvidas } \\
\text { com a utilização das TIC e centradas na } \\
\text { aprendizagem }\end{array}$ \\
\hline $\begin{array}{l}\text { Reconhecimento dos resultados positivos das TIC na } \\
\text { aprendizagem dos alunos }\end{array}$ & Integração das TIC na aprendizagem dos alunos \\
\hline Integração das TIC como mediadoras dos conteúdos & Integração das TIC como mediadoras dos conteúdos \\
\hline $\begin{array}{l}\text { Nível de familiaridade dos professores com as TIC (o } \\
\text { professor vincula os conteúdos à aplicação das TIC } \\
\text { para a aprendizagem do aluno) }\end{array}$ & $\begin{array}{l}\text { Nível de familiaridade dos professores com as TIC (o } \\
\text { professor vincula os conteúdos à aplicação das TIC } \\
\text { para a aprendizagem do aluno) }\end{array}$ \\
\hline $\begin{array}{l}\text { Percentual dos estudantes e dos docentes com } \\
\text { contas de correio eletrônico, weblog, página web } \\
\text { pessoal, ser membro em pelo menos uma rede social }\end{array}$ & $\begin{array}{l}\text { Percentual dos estudantes e dos docentes com } \\
\text { contas de correio eletrônico, weblog, página web } \\
\text { pessoal, ser membro em pelo menos uma rede social }\end{array}$ \\
\hline $\begin{array}{l}\text { TIC nos planos de aula e alguns tipos de programas } \\
\text { de avaliação formativa e sumativa }\end{array}$ & $\begin{array}{l}\text { TIC nos planos de aula e alguns tipos de programa de } \\
\text { avaliação formativa e sumativa }\end{array}$ \\
\hline Capacidade para trabalhar em rede & $\begin{array}{l}\text { Planos de aula que incluam o ensino das TIC: } \\
\text { processadores de textos, navegadores da web, } \\
\text { e-mails, blogs, weaks e outras tecnologias emergentes }\end{array}$ \\
\hline Capacidades básicas de utilização das TIC & Uso de ambientes virtuais de aprendizagem \\
\hline
\end{tabular}

Fonte: Dados da pesquisa.

Observa-se uma similaridade evidente na seleção dos indicadores considerados os mais importantes na análise do trabalho docente que utiliza as TIC, entre os professores portugueses e brasileiros. Dentre os dez indicadores mais votados, sete $(70 \%)$ foram os mesmos em ambos os casos. Também nessa primeira leitura evidencia-se que na opinião dos docentes, para uma avaliação adequada do uso das TIC, há três indicadores que estão de forma direta relacionados com a dimensão da aprendizagem do aluno e outros três que se referem à dimensão do trabalho de ensino. Isso significa que, para eles, existe uma relação indissociável entre a prática do ensino e os resultados com os alunos, sendo que as tecnologias precisam estar envolvidas nessa relação. 
A familiaridade dos professores com a utilização das TIC, em especial na dimensão relativa ao uso pessoal, é lembrada como importante para avaliação do trabalho docente nos outros quatro indicadores (40\%). Ao levar em consideração que os dez indicadores mais votados podem ser divididos em três grupos - centrados no ensino, na aprendizagem e no uso pessoal -, infere-se que, na opinião dos educadores, a destreza do uso e o costume de acesso às ferramentas tecnológicas na esfera extraclasse são fatores determinantes para a reflexão sobre as práticas pedagógicas que utilizam as TIC.

Esse resultado condiz com a necessidade evidente em uma sociedade da informação de se pensar a docência que integre as tecnologias como um tema transversal e não apenas em uma perspectiva instrumentalizada. Dessa maneira, as TIC deixam de ser apenas plataforma de conteúdo e passam a desempenhar o papel que possibilite ao professor reflexão sobre sua mediação na prática docente desde as habilidades de uso, a consciência crítica sobre o uso e seus resultados no planejamento pedagógico, perpassando pela autonomia na produção e divulgação, assim como pela reflexão sobre a ação do uso em sala e os resultados na aprendizagem.

Essa questão recai sobre os indicadores ligados ao uso pessoal das TIC. Para os professores, é fundamental a utilização constante dos dispositivos tecnológicos para que se construa um conhecimento acerca dos mesmos. Eles entendem que o nível e a frequência de utilização das TIC enquanto dispositivos de uso personificado, por meio de e-mails, acesso a notícias e entretenimento, também constituem fator determinante do sucesso das experiências pedagógicas que lançam mão desse subterfúgio. Aqui vale ressaltar que o uso pessoal das tecnologias é considerado importante por parte tanto do professor como do aluno. Com isso, é plausível a inferência de que essa dicotomia docente-discente norteia toda a compreensão dos professores acerca do trabalho pedagógico.

Os professores também julgam necessária a presença das TIC não apenas em um momento do processo educacional, mas em todas as etapas, sendo esse um indicador escolhido por $100 \%$ dos respondentes como fundamental para avaliação que se propõe. De acordo com o aferido nas respostas dadas ao 
questionário, eles consideram que a frequência de utilização das tecnologias no planejamento, execução e avaliação dos trabalhos junto aos alunos é outro fator determinante para o sucesso das experiências que levem em conta os dispositivos tecnológicos do Prouca e do Projeto Magalhães.

Apenas em três indicadores há discordância entre as escolhas feitas pelos brasileiros e portugueses. Para os educadores do Brasil, é importante avaliar como as TIC estão inseridas e contribuem para os processos de aprendizagem dos estudantes, fator pouco destacado pelos europeus. Em contrapartida, os portugueses enumeram como importantes as práticas que resultem em trabalho colaborativo e compartilhamento em rede.

Há também semelhanças e diferenças nos indicadores que receberam menos indicações pelos dois grupos, conforme exposto no Quadro 3.

QUADRO 3 - Indicadores menos votados

\begin{tabular}{|c|c|}
\hline PORTUGAL & BRASIL \\
\hline $\begin{array}{l}\text { Planos que incorporem/integrem: I - plataformas } \\
\text { on-line; programas tutorias; II - exercícios em formato } \\
\text { digital; III - recursos e conteúdos eletrônicos }\end{array}$ & $\begin{array}{l}\text { Planos que incorporem/integrem: I - plataformas } \\
\text { on-line; programas tutorias; || - exercícios em formato } \\
\text { digital; III - recursos e conteúdos eletrônicos }\end{array}$ \\
\hline Partilha de planificações com os pares & Partilha de planificações com os pares \\
\hline $\begin{array}{l}\text { Seleção de programas (software) específicos para os } \\
\text { conteúdos a lecionar }\end{array}$ & $\begin{array}{l}\text { Seleção de programas (softwares) específicos para os } \\
\text { conteúdos a lecionar }\end{array}$ \\
\hline $\begin{array}{l}\text { Conteúdos e produtos de aprendizagem produzidos e } \\
\text { publicados por professores com o apoio dos alunos }\end{array}$ & $\begin{array}{l}\text { Conteúdos e produtos de aprendizagem produzidos e } \\
\text { publicados por professores com o apoio dos alunos }\end{array}$ \\
\hline $\begin{array}{l}\text { Número de professores registrados que participam } \\
\text { dos sites educativos }\end{array}$ & $\begin{array}{l}\text { Número de professores registrados que participam } \\
\text { dos sites educativos }\end{array}$ \\
\hline $\begin{array}{l}\text { Número de recursos criados por professores e } \\
\text { disponibilizados em portal educativo nacional }\end{array}$ & $\begin{array}{l}\text { Número de recursos criados por professores e } \\
\text { disponibilizados em portal educativo nacional }\end{array}$ \\
\hline Horas de aulas com as TIC & Horas de aulas com as TIC \\
\hline $\begin{array}{l}\text { Número de recursos criados por professores em } \\
\text { relação ao total de recursos disponíveis em sites } \\
\text { educativos nacionais }\end{array}$ & $\begin{array}{l}\text { Número de recursos criados por professores em } \\
\text { relação ao total de recursos disponíveis em sites } \\
\text { educativos nacionais }\end{array}$ \\
\hline $\begin{array}{l}\text { Número de docentes que desenvolvem e partilham } \\
\text { conteúdos educativos }\end{array}$ & $\begin{array}{l}\text { Número de docentes que desenvolvem e partilham } \\
\text { conteúdos educativos }\end{array}$ \\
\hline $\begin{array}{l}\text { Professores envolvidos com as TIC (carga horária de } \\
\text { formação contínua em TIC) }\end{array}$ & $\begin{array}{l}\text { Professores envolvidos com as TIC (carga horária de } \\
\text { formação continuada em TIC) }\end{array}$ \\
\hline
\end{tabular}

Fonte: Dados da pesquisa.

Quanto aos indicadores classificados como menos importantes, verifica-se de início a percepção semelhante dos dois 
grupos em relação à seleção. Todos os dez indicadores menos selecionados foram os mesmos na percepção dos professores brasileiros e portugueses. A primeira inferência está relacionada à dimensão produção/publicação. Apesar de considerarem a produção em rede positiva para o processo de educação mediada pelas TIC, os professores não pensam as etapas como partilha de conteúdos entre pares, publicação de conteúdos e participação em sites educativos como significativas na avaliação da TIC na docência, que estejam inseridas num contexto informacional. Esse resultado leva ao questionamento sobre qual o entendimento desses professores acerca do trabalho colaborativo e em rede. Há que se refletir o quanto os educadores de fato compreendem o contexto e as possibilidades advindas do uso das TIC e relacionam estes à sua própria capacidade de autoria, produção e divulgação de conteúdos, mais adequadas a suas realidades em sala.

Outro fator revelado a partir da leitura dos dados é a percepção dos professores referente aos espaços on-line de aprendizagem, como, por exemplo, os ambientes virtuais de aprendizagem, e aos softwares específicos voltados para a educação. Embora tenham afirmado nas entrevistas que a internet pode se caracterizar como um espaço de incentivo à dispersão e ao plágio, eles demonstram pensar a utilização de sítios especificamente educacionais como indicadores pouco importantes na avaliação das abordagens pedagógicas que utilizam as TIC.

Em relação à quantidade de horas destinadas à formação para o uso das tecnologias ou para o desenvolvimento de atividades em sala com as mesmas, verifica-se a pouca relevância atribuída pelos professores a esses indicadores. De acordo com o respondido, essa carga horária não avalia a concretização da aprendizagem pela tecnologia, outra reflexão importante feita a partir da pesquisa. Para esse item, destacamos os relatos da maioria dos professores nas entrevistas sobre a ineficiência das formações das quais participaram e, principalmente, em relação ao número insuficiente de horas dessas experiências formativas para o desenvolvimento de competências de uso das TIC no espaço escolar. As pontuações sobre a qualidade e o tempo das experiências de formação continuadas estão presentes em quase todos os 
resultados de avaliação que envolva essa dimensão nos estudos acadêmicos no Brasil.

Por fim, o questionário trouxe uma questão aberta para os professores apresentarem outros indicadores não contemplados ali, mas que eles consideram relevantes na avaliação da prática docente mediada pelas TIC. Essa última parte do instrumento trouxe sugestões de indicadores que podem ser divididos em três dimensões: profissional (formações necessárias para o trabalho com as TIC; softwares utilizados em nível profissional; manutenção de máquinas e acesso à internet); pessoal (perfil de gênero e idade; sites acessados em casa); e aprendizagem (modelos que considerem aprendizagem colaborativa; modelos que considerem aprendizagem autônoma).

\section{CONCLUSÕES}

As reflexões que consideram o lugar das TIC na sociedade atual, pensadas sob a perspectiva da sociedade da informação e do conhecimento, são unânimes em reconhecer que as tecnologias digitais da comunicação exercem papel relevante na realização de atividades da vida cotidiana e daquelas direta ou indiretamente relacionas aos processos de aprendizagem. Nesse contexto, são exigidas mudanças nas abordagens pedagógicas, que deixam de reproduzir modelos de repetição para privilegiar práticas de aprendizagem voltadas para a formação de sujeitos autônomos, inovadores e que dominam as competências necessárias para o uso das tecnologias.

Algumas experiências procuraram desenvolver no espaço escolar essa perspectiva, caso dos programas Prouca e Magalhães, mas ainda não produziram indicadores consistentes para consolidar modelos que avaliem as formas de uso das tecnologias por professores e o impacto dessa utilização nos processos de aprendizagem. Pensar esses instrumentos avaliativos implica conhecer como os professores relacionam-se com as TIC e como pensam, constroem, aplicam e avaliam os métodos que podem avaliar suas práticas docentes.

Os resultados deste estudo mostram que os próprios professores reconhecem a necessidade de uma formação mais completa e continuada para estimular o desenvolvimento de 
habilidades na utilização das tecnologias. Eles também consideram fundamental que o uso das TIC seja efetivado em todas as etapas do procedimento pedagógico, desde o planejamento de aulas e atividades até a mensuração dos resultados dos alunos.

Contudo, é percebido que os professores ainda conhecem e reconhecem pouco as possibilidades que residem na prática docente mediada por tecnologias. Eles demonstram pouco esclarecimento em relação ao trabalho em rede, colaborativo, e ainda apresentam resistência em disponibilizar sua produção na web, produção que tende a ser apenas textual, desconsiderando recursos audiovisuais comuns aos dispositivos digitais.

No que diz respeito à possibilidade de utilização de indicadores para avaliar o uso das TIC na prática docente, os professores colaboradores relacionaram 27 indicadores, dos quais destacam-se, na percepção dos dois grupos, os que versam sobre as dimensões da utilização das tecnologias em sala de aula, da produção e compartilhamento de conteúdos e, principalmente, os relacionados ao uso das TIC nos momentos de planejamento das aulas.

Como próximo passo deste estudo, está sendo desenvolvido um instrumento com esses indicadores que será aplicado para professores brasileiros, no sentido de validar o instrumento e apresentar resultados que contribuam para compreender o uso das TIC por professores e seu impacto na prática docente.

\section{REFERÊNCIAS}

ALMEIDA, M. E. B.; ASSISI, M. P. Integração da Web 2.0 ao currículo: a geração web currículo. La Educ@cion: revista digital, n. 145, Mayo 2011. Disponível em: <http://www.educoea.org/portal/La_Educacion_Digital/145/ articles/ART_bianconcini_ES.pdf>. Acesso em: maio 2014.

ALVAREZ, C. A. 0 programa "Um Computador por Aluno" no Brasil: uma história e experiência por concluir. 2015. 238 f. Tese (Doutorado em Educação em Ciências) - Programa de Pós-Graduação em Educação em Ciências: Química da Vida e Saúde, da Universidade Federal do Rio Grande do Sul, Porto Alegre, 2015.

ASOCIACIÓN ESPAÑOLA DE NORMALIZACÓN Y CERTIFICACIÓN. Sistemas de gestión de la calidad: guía para la implantación de sistemas de indicadores. Madrid: Aenor, 2003. 
BANCO MUNDIAL. Knowledge maps: ICT in education. Washington, DC: InfoDev, 2015. Disponível em: <http://www.infodev.org/en/ Publication.8.html>. Acesso em: 20 jul. 2015.

CARVALHO, H. G. Tecnologias, inovação e educação: chaves para a competitividade. Revista Educação \& Tecnologia, Curitiba, n. 3, 2011. Disponível em: <http://revistas.utfpr.edu.br/pb/index.php/revedutec-ct/article/ view/1035/640>. Acesso em: jun. 2014

CASTELLS, M. A sociedade em rede. 2. ed. Tradução de Roneide Venâncio Majer. São Paulo: Paz e Terra, 1999.

COMITÊ GESTOR DA INTERNET NO BRASIL. Educação e tecnologias no Brasil: um estudo de caso longitudinal sobre o uso das tecnologias da informação e comunicação em 12 escolas públicas. São Paulo: CGI.br, 2016.

CORTEZ, J.; LAU, J. Habilidades informativas: convergencia conceptual entre las ciencias de la información y la comunicación. Comunicar: Revista Científica Iberoamericana de Comunicación y Educación, v. 16, n. 32, p. 21-30, mar. 2009

FERRER, A. T. Indicadores de evaluación en educación. 2006. Disponível em: <http:/l redes-cepalcala.org/inspector/DOCUMENTOS\%20Y\%20LIBROS/EVALUACION/ INDICADORES\%20DE\%20EVALUACION\%20EN\%20EDUCACION.doc>. Acesso em: mar. 2015

FISCHER, R. M. B.; MARCELLO, F. A.; SHWERTNER, S. F. O estatuto pedagógico da mídia (telejornalismo e "formação"). In: SEMINÁRIO NACIONAL DA ANPED, 20., 1997, Caxambu. Anais... Caxambu: Anped, 1997. Disponível em: <http://www.portalanpedsul.com.br/admin/ uploads/1999/Educacao_E_Comunicacao_-_Tecnologias_Educacionais/ Trabalho/06_26_13_O_ESTATUTO_PEDAGOGICO_DA_MIDIA (TELEJORNALISMO_E_\%20FORMACAO\%20).pdf>. Acesso em: jan. 2017.

GENGNAGEL, C. L.; NICOLODI, F. Políticas públicas de conexão: desafios do século XXI. In: SEMINÁRIO ANPED SUL, 9., 2012, Caxias do Sul. Anais.. Caxias do Sul: Universidade de Caxias do Sul, 2012. Disponível em: <http://www.portalanpedsul.com.br/2012/home>. Acesso em: jun. 2015.

KENNISNET FOUDATION. Four in balance monitor 2015: use and benefits of ICT in education. Zoetermeer: Kennisnet, 2015.

MORDUCHOVICZ, A. Los indicadores educativos y las dimensiones que los integran. Buenos Aires: Unesco, 2006.

ORGANISATION FOR ECONOMIC CO-OPERATION AND DEVELOPMENT. High-quality education and training for all. Paris: OECD, 1992.

ORGANIZAÇÃO DAS NAÇÕES UNIDAS PARA A EDUCAÇÃO, A CIÊNCIA E A CULTURA. Computador na escola: a dura realidade nas escolas. TICs nas Escolas, v. 3, n. 1, 2008a. Disponível em: <http://unesdoc.unesco.org/ images/0015/001585/158527por.pdf>. Acesso em: fev. 2017.

ORGANIZAÇÃO DAS NAÇÕES UNIDAS PARA A EDUCAÇÃO, A CIÊNCIA E A CULTURA. Padrões de competência em TIC para professores: módulo de padrão de competência. Paris: Unesco, 2008b. Disponível em: <http:/unesdoc.unesco. org/images/0015/001562/156207por.pdf>. Acesso em: 23 set. 2015. 
ORGANIZAÇÃO DAS NAÇÕES UNIDAS PARA A EDUCAÇÃO, A CIÊNCIA E A CULTURA; COMISSÃO ECONÔMICA PARA A AMÉRICA LATINA E O CARIBE.

ICTs and education indicators: suggested core indicators based on meta-analysis of selected International School. Surveys. Québec: Unesco, 2006. Disponível em: <http://www.itu.int/ITU-D/ict/partnership/material/ICT_Education_ Paper_Nov_2006.pdf. 2006>. Acesso em: jan. 2015.

ORGANIZAÇÃO DOS ESTADOS IBERO-AMERICANOS; INSTITUTO PARA O DESENVOLVIMENTO E INOVAÇÃO EDUCATIVA; FUNDAÇÃO TELEFÔNICA. Indicadores cualitativos de la integración de las TICs en la educación: proposiciones. Brasil. OES, 2008. Disponível em: <http://www.oei-idietics.org/IMG/pdf/ Documento_Indicadores_IDIE_2008.pdf $>$. Acesso em: jan. 2016.

SIERRA, J. M. C. Sistema básico de indicadores para la educación superior de América Latina. València: Universitat Politècnica de València, 2012.

SILVA, M. A sala de aula interativa. Rio de Janeiro: Quartet, 2006.

SOUSA, B. Magalhães, o computador. Ozarfaxinars, n. 6, mar. 2009. Disponível em: <http://www.cfaematosinhos.eu/Magalhaes_o_Computador.pdf $>$. Acesso em: jun. 2015.

TAKAHASHI, T. (Org.). Sociedade da informação no Brasil: livro verde. Brasília, DF: MCT, 2000.

\section{RONALDO NUNES LINHARES}

Professor do Programa de Pós-Graduação em Educação da Universidade Tiradentes (Unit/PPED), Aracaju, Sergipe, Brasil ronaldo_linhares@unit.br

MARIA JOSÉ LOUREIRO

Professora da Universidade de Aveiro (UA), Aveiro, Portugal zeloureiro@ua.pt

\section{FERNANDO RAMOS}

Professor da Universidade de Aveiro (UA), Aveiro, Portugal fernando.ramos@ua.pt

\section{CAIO MÁRIO GUIMARÃES ALCÂNTARA}

Mestrando do Programa de Pós-Graduação em Educação da Universidade Tiradentes (Unit/PPED), Aracaju, Sergipe, Brasil caiogmalcantara@gmail.com 